\title{
Association between Abnormal Liver Function and Risk Factors for Metabolic Syndrome among Freshmen
}

\author{
Ping-Yun Tsai, M.D. ${ }^{a}$, Chung-Jen Yen, M.D. ${ }^{\mathrm{b}}$, Yi-Chin Li, M.D., M.P.H. ${ }^{\mathrm{b}}$, \\ Tai-Yuan Chiu, M.D. ${ }^{a}$, Ching-Yu Chen, M.D. ${ }^{a}$, and Chyi-Feng Jan, M.D., Ph.D. ${ }^{\text {a,* }}$ \\ ${ }^{a}$ Department of Family Medicine, National Taiwan University Hospital, Taipei, Taiwan \\ ${ }^{b}$ Health Center, Office of Student Affairs, National Taiwan University, Taipei, Taiwan \\ Manuscript received October 26, 2006; manuscript accepted March 22, 2007
}

\begin{abstract}
Purpose: The aim of this study was to investigate the prevalence of obesity and metabolic syndrome among freshmen and to find the association between abnormal liver function and risk factors for metabolic syndrome in Taiwan.

Methods: A total of 515 freshmen who were less than 22 years of age and negative for hepatitis B surface antigen marker from one general university in North Taiwan participated in this study during their school entry health examination in September 2004. Demographic characteristics, body height, body weight, biochemistry values such as alanine aminotransferase, and risk factors for metabolic syndrome such as blood pressure, fasting blood sugar, high-density lipoprotein cholesterol, triglycerides, and waist circumference were recorded for statistical analysis. Subjects with elevated serum alanine aminotransferase levels were considered to have abnormal liver function.

Results: The prevalence of overweight, obesity, and metabolic syndrome among freshmen in Taiwan was $18.5 \%, 6.0 \%$ and $1.4 \%$, respectively. The prevalence of abnormal liver function test was $6.2 \%$. In multivariate logistic regression analyses, patients of metabolic syndrome were 94.5 times more likely $(95 \%$ confidence interval $[\mathrm{CI}]=10.5-852.5)$ to be associated with abnormal liver function after adjusting for gender and age. Among the risk factors for metabolic syndrome, enlarged waist circumference (adjusted odds ratio $[\mathrm{OR}]=10.1,95 \% \mathrm{CI}=4.3-23.8$ ), and elevated triglyceride (adjusted $\mathrm{OR}=6.1,95 \% \mathrm{CI}=1.6-23.5$ ) were found to be statistically significantly associated with abnormal liver function.

Conclusions: Central obesity and elevated triglyceride level were the two risk factors for metabolic syndrome associated with abnormal liver function among freshmen in Taiwan. (C) 2007 Society for Adolescent Medicine. All rights reserved.
\end{abstract}

Keywords:

Metabolic syndrome; Nonalcoholic fatty liver disease; Freshmen; Abnormal liver function

Obesity and metabolic syndrome are well-known major predisposing conditions to nonalcoholic fatty liver disease (NAFLD) [1,2]. NAFLD is being increasingly recognized as a common liver disorder that represents the hepatic manifestation of the metabolic syndrome, a variably defined aggregate of disorders related to obesity, insulin resistance,

\footnotetext{
*Address correspondence to: Dr. Chyi-Feng Jan, Department of Family Medicine, National Taiwan University Hospital, National Taiwan University, Taipei, Taiwan \#7, Chung San South Rd., Taipei, 100, Taiwan, R.O.C.

E-mail address: mandible@ha.mc.ntu.edu.tw
}

type 2 diabetes, hypertension, and hyperlipidemia [3]. NAFLD encompasses the entire spectrum of liver disease, which includes simple hepatic steatosis without inflammation, nonalcoholic steatohepatitis (NASH), and the resulting cirrhosis and end-stage liver disease [4]. Hepatocellular carcinoma is a documented complication in an as yet unknown percentage of cases of NASH-related cirrhosis [3].

Excluding viral hepatitis, alcoholic liver disease, hematochromatosis, and metabolic liver disease, NAFLD is the most common liver disease in developed countries [2,5]. Unexplained aminotransferase elevation was found to be 
strongly associated with adiposity and other features of the metabolic syndrome, and thus may represent NAFLD [6]. In the early 1980s, the positive rate of hepatitis B surface antigen $(\mathrm{HBsAg})$ in the general population of Taiwan was as high as $15-20 \%$. [7]. Since universal hepatitis B vaccination was launched in 1984, the carrier rate of hepatitis B has declined [8]. However, the prevalence of metabolic syndrome is increasing because of the rising prevalence of childhood and adolescent obesity. The prevalence of metabolic syndrome for adults in Taiwan is about $10-15 \%$ $[9,10]$. Therefore, NAFLD may become the most common liver disease among children and adolescents in the future, after hepatitis B infection has been controlled with mass vaccination.

The majority of college freshmen are in the late adolescent stage and are commonly considered as young adults. Despite the copious studies published on metabolic syndrome in recent years, few have focused on individuals in this transitional period. Therefore, the aim of our study is to investigate the prevalence of obesity and metabolic syndrome in freshmen and to delineate the association between abnormal liver function and variable risk factors for metabolic syndrome.

\section{Subjects and Methods}

\section{Study design}

We conducted a cross-sectional study to see the association between risk factors for metabolic syndrome and abnormal liver function among freshmen who were less than 22 years of age and negative for hepatitis B surface antigen marker.

\section{Data sources}

The majority of the freshmen attending the selected university received routine school entrance health examination during an 8-day scheduled period. We randomly sampled 1 day's attendants as the study subjects. Those who were more than 22 years of age or positive for hepatitis B surface antigen marker were excluded; thus 515 persons were randomly selected from 4,013 freshmen in one university in Taipei city, Taiwan in 2004. All of the study subjects signed informed consent proved by school health committee and the ClinicalTrials.gov identifier was NCT00173940. Questionnaires, physical examination, and blood tests were performed by medical staffs from the university hospital and health center.

\section{Definitions}

The metabolic syndrome was defined using the modified diagnostic criteria of the 2005 International Diabetes Federation consensus in Asian populations [11]. With a lower waist circumference cut-off, the prevalence of the metabolic syndrome was comparable to that in Western populations
[12]. Risk factors for metabolic syndrome included central obesity (defined as waist circumference $\geq 90 \mathrm{~cm}$ for men and $\geq 80 \mathrm{~cm}$ for women, according to ethnicity-specific values for Chinese individuals [13]) plus any two of the following four variables: elevated blood pressure (systolic blood pressure $\geq 130 \mathrm{~mm} \mathrm{Hg}$ or diastolic blood pressure $\geq 85 \mathrm{~mm} \mathrm{Hg}$, or treatment of previously diagnosed hypertension); raised serum triglyceride level $(\geq 150 \mathrm{mg} / \mathrm{dL}$, or specific treatment for this lipid abnormality); reduced highdensity lipoprotein cholesterol (HDL-C; $<40 \mathrm{mg} / \mathrm{dL}$ in males and $<50 \mathrm{mg} / \mathrm{dL}$ in females, or specific treatment for this lipid abnormality); and raised fasting glucose $\geq 100$ $\mathrm{mg} / \mathrm{dL}$ or previously diagnosed type 2 diabetes. Body mass index (BMI) cutoffs were adopted as suggested by the Department of Health in Taiwan including normal (BMI $\geq 18.5 \mathrm{~kg} / \mathrm{m}^{2}$ but $<24 \mathrm{~kg} / \mathrm{m}^{2}$ ), overweight (BMI $\geq 24 \mathrm{~kg} / \mathrm{m}^{2}$ but $<27 \mathrm{~kg} / \mathrm{m}^{2}$ ), and obese (BMI $\geq 27 \mathrm{~kg} / \mathrm{m}^{2}$ ) categories. Subjects with elevated serum alanine aminotransferase (ALT) levels (ALT $\geq 41 \mathrm{U} / \mathrm{L}$ in men and $\geq 31 \mathrm{U} / \mathrm{L}$ in women, according to the University Hospital laboratory reference) were considered to have abnormal liver function test (LFT).

\section{Serum viral markers and biochemistry}

HBsAg was detected using radioimmunoassay kits by DADE Behring, Rosys Beh III, and Abbott. Fasting plasma glucose, serum triglyceride, and HDL levels were measured using standard laboratory tests at the university hospital.

\section{Statistical analysis}

SAS version 9.1 software (SAS Institute, Cary, NC) was used for statistical analysis. $\chi^{2}$ Analysis and Fisher's exact test were used to identify factors influencing the differences in liver function in persons with metabolic risk factors. Multivariate logistic regression analysis was performed to see the association between metabolic syndrome and abnormal liver function after adjusting for age and gender taken metabolic syndrome as an independent variable. Furthermore, stepwise multivariate logistic regression analyses were done to identify the odds ratios of abnormal LFT with regard to the different risk factors for metabolic syndrome after adjusting for age and gender. Odds ratios (OR) and 95\% confidence intervals (95\% CI) were also calculated. Statistical significance throughout was set at 5\%.

\section{Results}

After exclusion of 40 individuals who were more than 22 years of age or positive for hepatitis B surface antigen marker, 515 freshmen were included in the final analysis. Among them, 271 were male (52.6\%). Their mean age was $18.9 \pm 0.8$ years, and their mean BMI was $21.4 \pm 3.5$ $\mathrm{kg} / \mathrm{m}^{2}$. The data distribution for age, BMI, risk factors for metabolic syndrome, and ALT among the study subjects by gender is shown on Table 1. The prevalence of overweight, obesity, and metabolic syndrome was $18.5 \%, 6.0 \%$ and 
Table 1

Data distribution of age, body mass index, risk factors for metabolic syndrome, and alanine aminotransferase among the study subjects $(n=515)$

\begin{tabular}{lcccc}
\hline Item & $\begin{array}{l}\text { No. }(\%) \\
(\mathrm{n}=515)\end{array}$ & $\begin{array}{l}\text { Males } \\
(\mathrm{n}=271)\end{array}$ & $\begin{array}{l}\text { Females } \\
(\mathrm{n}=244)\end{array}$ & $p$ \\
\hline Age (years) & $18.9 \pm 0.8$ & $18.9 \pm 0.8$ & $18.8 \pm 0.8$ & .15 \\
Body mass index (kg/m $\left.{ }^{2}\right)$ & $21.4 \pm 3.5$ & $22.3 \pm 3.5$ & $20.4 \pm 2.6$ & $<.0001$ \\
Waist circumference (cm) & $72.5 \pm 10.1$ & $77.1 \pm 10.6$ & $67.3 \pm 6.4$ & $<.0001$ \\
Blood pressure (mm Hg) & & & & \\
$\quad$ Systolic (mm Hg) & $116.2 \pm 15.8$ & $122.5 \pm 14.4$ & $109.2 \pm 14.2$ & $<.0001$ \\
$\quad$ Diastolic (mm Hg) & $66.6 \pm 10.4$ & $68.9 \pm 10.0$ & $64.1 \pm 10.3$ & $<.0001$ \\
Triglyceride (mg/dL) & $66.5 \pm 48.9$ & $70.2 \pm 41.7$ & $62.5 \pm 55.6$ & .59 \\
HDL-cholesterol (mg/dL) & $46.4 \pm 9.4$ & $46.4 \pm 9.7$ & $46.4 \pm 9.1$ & .85 \\
LDL-cholesterol (mg/dL) & $106.8 \pm 29.8$ & $107.7 \pm 30.1$ & $105.7 \pm 29.5$ & .38 \\
Total cholesterol (mg/dL) & $163.9 \pm 26.8$ & $162.6 \pm 26.3$ & $165.2 \pm 27.3$ & .30 \\
Fasting glucose (mg/dL) & $92.9 \pm 8.4$ & $94.5 \pm 9.2$ & $92.9 \pm 8.4$ & $<.0001$ \\
Alanine aminotransferase (U/L) & $17.3 \pm 18.4$ & $21.5 \pm 22.3$ & $17.3 \pm 18.4$ & $<.0001$ \\
\hline
\end{tabular}

Data are mean \pm SD.

$\mathrm{HDL}=$ high-density lipoprotein; $\mathrm{LDL}=$ low-density lipoprotein.

$1.4 \%$, respectively. We identified 32 persons with abnormal LFT $(6.2 \%)$ and 483 persons with normal LFT, set as the control group (93.8\%). The results of persons with metabolic risk factors in abnormal LFT subgroup compared with those with normal LFT are shown in Table 2. Waist circumference, blood pressure, triglycerides, HDL-C, and metabolic syndrome disclosed significant differences in the two subgroups. The mean ALT value was $74.7 \pm 40.5$ $\mathrm{U} / \mathrm{L}$ for those who had metabolic syndrome, and $16.6 \pm$ 16.7 U/L for those who did not have metabolic syndrome $(p<.05)$. In univariate logistic regression analysis, factors which were related to abnormal LFT were enlarged waist circumference, elevated triglyceride, elevated blood pressure, and reduced HDL-C. The ORs and 95\% CIs are shown in Table 3. The multivariate logistic regression analyses revealed that individuals with metabolic syndrome were 94.5 times more likely $(95 \% \mathrm{CI}=$ 10.5-852.5) to have abnormal LFT after adjusting for gender, and age (Table 4). Among the risk factors for metabolic syndrome, enlarged waist circumference (adjusted $\mathrm{OR}=10.1,95 \% \mathrm{CI}=4.3-23.8)$ and elevated triglyceride (adjusted OR $=6.1 .95 \% \mathrm{CI}=1.6-23.5$ ) were statistically significantly associated with abnormal LFT after adjusting for gender and age (Table 5).

Table 2

Comparison of risk factors for metabolic syndrome in abnormal liver function subgroup compared with normal liver function subgroup

\begin{tabular}{|c|c|c|c|c|}
\hline Variable & $\begin{array}{l}\text { No. }(\%) \\
(\mathrm{n}=515)\end{array}$ & $\begin{array}{l}\text { Abnormal liver function } \\
(\mathrm{n}=32)\end{array}$ & $\begin{array}{l}\text { Normal liver function } \\
(\mathrm{n}=483)\end{array}$ & $p$ \\
\hline \multicolumn{5}{|l|}{ Waist circumference } \\
\hline$<90 \mathrm{~cm}$ in males, $<80 \mathrm{~cm}$ in females & $476(92.4)$ & $18(56.3)$ & $458(94.8)$ & $<.0001^{\mathrm{a}}$ \\
\hline \multicolumn{5}{|l|}{ Blood pressure } \\
\hline Systolic $\geq 130$ or diastolic $\geq 85 \mathrm{~mm} \mathrm{Hg}$ & $93(18.1)$ & $12(37.5)$ & $81(16.8)$ & $.003^{\mathrm{a}}$ \\
\hline$\geq 150 \mathrm{mg} / \mathrm{dL}$ & $13(2.5)$ & $6(18.8)$ & $7(1.5)$ & \multirow[t]{2}{*}{$<.0001^{\mathrm{a}}$} \\
\hline$<150 \mathrm{mg} / \mathrm{dL}$ & $502(97.5)$ & $26(81.3)$ & $476(98.6)$ & \\
\hline \multicolumn{5}{|l|}{ High-density lipoprotein cholesterol } \\
\hline$<40 \mathrm{mg} / \mathrm{dL}$ in males, $<50 \mathrm{mg} / \mathrm{dL}$ in females & $238(46.2)$ & $8(25.0)$ & $230(47.6)$ & \multirow[t]{2}{*}{$.013^{\mathrm{b}}$} \\
\hline$\geq 40 \mathrm{mg} / \mathrm{dL}$ in male, $\geq 50 \mathrm{mg} / \mathrm{dL}$ in females & $277(53.8)$ & $24(75.0)$ & $253(52.4)$ & \\
\hline \multicolumn{5}{|l|}{ Fasting glucose } \\
\hline No & $508(98.6)$ & $26(81.3)$ & $482(99.8)$ & $<.0001^{\mathrm{a}, \mathrm{c}}$ \\
\hline
\end{tabular}

a $p<.01$.

${ }^{\mathrm{b}} p<.05$.

${ }^{\mathrm{c}}$ Fisher's exact test. 
Table 3

Univariate logistic regression analysis to evaluate the association between risk factors for metabolic syndrome and abnormal liver function

\begin{tabular}{|c|c|c|c|}
\hline Variables & OR & $95 \% \mathrm{CI}$ & $p$ \\
\hline \multicolumn{4}{|l|}{ Waist circumference } \\
\hline$\geq 90 \mathrm{~cm}$ in males, $\geq 80 \mathrm{~cm}$ in females & 14.2 & $6.4-31.9$ & $<.0001^{\mathrm{a}}$ \\
\hline$<90 \mathrm{~cm}$ in males, $<80 \mathrm{~cm}$ in females & 1 & & \\
\hline \multicolumn{4}{|l|}{ Blood pressure } \\
\hline Systolic $\geq 130$ or diastolic $\geq 85 \mathrm{~mm} \mathrm{Hg}$ & 3.0 & $1.4-6.3$ & $.005^{\mathrm{a}}$ \\
\hline Systolic $<130$ and diastolic $<85 \mathrm{~mm} \mathrm{Hg}$ & 1 & & \\
\hline \multicolumn{4}{|l|}{ Triglycerides } \\
\hline$\geq 150 \mathrm{mg} / \mathrm{dL}$ & 15.7 & $4.9-50.0$ & $<.0001^{\mathrm{a}}$ \\
\hline$<150 \mathrm{mg} / \mathrm{dL}$ & 1 & & \\
\hline \multicolumn{4}{|l|}{ High-density lipoprotein cholesterol } \\
\hline$<40 \mathrm{mg} / \mathrm{dL}$ in males, $<50 \mathrm{mg} / \mathrm{dL}$ in females & 0.37 & $0.2-0.8$ & $.017^{\mathrm{b}}$ \\
\hline$\geq 40 \mathrm{mg} / \mathrm{dL}$ in males, $\geq 50 \mathrm{mg} / \mathrm{dL}$ in females & 1 & & \\
\hline \multicolumn{4}{|l|}{ Fasting glucose } \\
\hline$\geq 100 \mathrm{mg} / \mathrm{dL}$ & 1.3 & $0.5-3.3$ & .558 \\
\hline$<100 \mathrm{mg} / \mathrm{dL}$ & 1 & & \\
\hline \multicolumn{4}{|l|}{ Metabolic syndrome } \\
\hline Yes & 111.2 & $12.9-958.1$ & $<.0001^{\mathrm{a}}$ \\
\hline No & 1 & & \\
\hline
\end{tabular}

\section{Discussion}

Tissue biopsy is the gold standard for the confirmation of steatohepatitis, NASH, or NAFLD; however the feasibility of liver biopsy as a mass screening method is low, and therefore abnormal ALT levels have been used as surrogate marker of steatohepatitis in previous studies $[3,6,14] \mathrm{We}$ also used elevated serum ALT levels to imply possible NAFLD after the exclusion of individuals with hepatitis B infection, since liver diseases such as hepatitis caused by mononucleosis syndrome from Epstein-Barr virus or cytomegalovirus infections in our study population were rare [15].

Our data showed that the prevalence of metabolic syndrome among freshmen is $1.4 \%$, which is much lower than adults in Taiwan (15\%). There are two important findings

Table 4

Multivariate logistic regression analysis to evaluate association between metabolic syndrome and abnormal liver function test results

\begin{tabular}{lccc}
\hline Variables & OR & $95 \%$ CI & $p$ \\
\hline Age & & & .74 \\
$\quad$ Continuous variable & 0.9 & $0.6-1.5$ & \\
Sex & 1 & & $.016^{\mathrm{a}}$ \\
$\quad$ Male & 3.0 & $1.2-7.5$ & \\
$\quad$ Female & 1 & & \\
Metabolic syndrome & & & \\
$\quad$ Yes & 94.5 & $10.5-852.5$ & \\
$\quad$ No & 1 & &
\end{tabular}

$\mathrm{CI}=$ confidence interval; $\mathrm{OR}=$ odds ratio.

${ }^{\mathrm{a}} p<.05$.

${ }^{\mathrm{b}} p<.01$. from this study; .First, individuals with metabolic syndrome is noted to have 94.5 times higher $(95 \% \mathrm{CI}=10.5-852.5)$ risk of abnormal liver function test as compared to those without. Second, enlarged waist circumference and elevated triglyceride levels were the two metabolic factors associated with abnormal LFT even after adjusting for age and gender.

Our findings in freshmen were in agreement with previous studies, which disclosed that metabolic syndrome is a strong predictor of NAFLD in adults [16-20]. A study by Shen et al showed that the presence of bright liver and elevated ALT level was independently associated with in-

Table 5

Multivariate logistic regression analysis to evaluate the association between risk factors for metabolic syndrome and abnormal liver function

\begin{tabular}{|c|c|c|c|}
\hline Variable & OR & $95 \% \mathrm{CI}$ & $p$ \\
\hline \multicolumn{4}{|l|}{ Age } \\
\hline Continuous variable & $\begin{array}{l}0.9 \\
1\end{array}$ & $0.6-1.5$ & .76 \\
\hline Sex & & & \\
\hline $\begin{array}{l}\text { Male } \\
\text { Female }\end{array}$ & $\begin{array}{l}2.5 \\
1\end{array}$ & $1.0-6.3$ & $.046^{\mathrm{a}}$ \\
\hline $\begin{array}{l}\text { Waist circumference } \\
\geq 90 \mathrm{~cm} \text { in males, } \geq 80 \mathrm{~cm} \\
\text { in females } \\
<90 \mathrm{~cm} \text { in males, }<80 \mathrm{~cm} \\
\text { in females }\end{array}$ & 10.1 & $4.3-23.8$ & $<.0001^{\mathrm{b}}$ \\
\hline $\begin{array}{l}\text { Triglycerides } \\
\quad \geq 150 \mathrm{mg} / \mathrm{dL} \\
\quad<150 \mathrm{mg} / \mathrm{dL}\end{array}$ & $\begin{array}{l}6.1 \\
1\end{array}$ & $1.6-23.5$ & $.009^{\mathrm{b}}$ \\
\hline
\end{tabular}

$\mathrm{CI}=$ confidence interval; $\mathrm{OR}=$ odds ratio.

${ }^{\mathrm{a}} p<.05$.

${ }^{\mathrm{b}} p<.01$. 
creased risk of metabolic syndrome in adults [16]. With regard to adolescents or young adults, in a study in Korean adolescents, metabolic syndrome was strongly associated with elevated ALT level, and the risk for elevated ALT level increases with the number of components of metabolic syndrome [20]. However, the Dionysos nutrition and liver study conducted in Italy revealed that NAFLD is associated with numerous features of the metabolic syndrome instead of elevated ALT level only [21].

With regard to individual components of the metabolic syndrome, enlarged waist circumference was much more likely to have abnormal LFT in our study, which was also comparable to results of previous studies in adults and children [17,20,22,23-26]. Increasing evidence shows that abdominal adiposity has a direct influence on health, and waist circumference is a reliable indicator of visceral fat and central adiposity, which correlates with health risks to a greater extent than does adipose tissue in other regions of the body because of high association between the visceral fat and insulin resistance [27-29].

NAFLD is the resultant disequilibrium in lipid homeostasis, which causes triglycerides to accumulate in the liver. An increase in oxidative stress, caused by the generation of reactive oxygen species as a result of mitochondrial abnormalities and induction of the cytochrome P-450 system, could be one mechanism by which NAFLD develops into NASH [30]. In addition to central obesity, elevated triglyceride level was also noted to have high association with elevated ALT level in our subjects. It has also been found to be associated with hepatic steatosis or NAFLD in adults $[6,17,20]$ and in children $[24,26]$. Because enlarged waist circumference and elevated triglycerides had been identified as components of a syndrome of lipid overaccumulation associated with metabolic risk and accelerated mortality after middle age [31], our study likewise showed similar trends thus indicating that clinicians should provide closer follow-up of adolescents or young adult patients with central obesity or hypertriglyceridemia.

In regard to the association of HDL-C and abnormal LFT, the result of univariate logistic regression analysis in our study showed that lower HDL-C was associated with $63 \%$ lowered risk $(95 \% \mathrm{CI}=17-84 \%)$ of abnormal LFT. Its negative association remained after adjustment for age and gender, although this was not statistically significant. The result was quite different from other studies, which disclosed low HDL-C associated with elevated ALT level in adults or obese adolescents with suspected fatty liver $[6,17,20,32]$. It is known that lipid composition varies by puberty stage in youth. Total cholesterol drops in mid-puberty and begins rising toward adult levels at the end of puberty $[33,34]$. These lipid changes throughout puberty complicate the definition of cut-off points for dyslipidemia in young persons. Therefore, the appropriateness of the HDL-C cutoff value for the metabolic syndrome in young adults is questionable. On the other hand, racial/ethnic dif- ferences may be the cause of this discrepancy. Further research is needed to explore this issue.

Apart from central obesity and elevated triglyceride level, there were no obvious association between HDL-C, high blood pressure or impaired fasting glucose and abnormal LFT after adjusting for age and gender. Hypertension has been recognized as an important component of the metabolic syndrome in adults, but its role in children and adolescents is still not clear [35]. Few studies of youth have examined the relationship of blood pressure and insulin values, and their results are conflicting. Some investigators found a positive association between insulin levels and blood pressure [36,37], whereas others did not [38,39].

There are several limitations to our study. First, the sample size of abnormal LFT subgroup was relatively small (32 cases). However, we could still find a significant association between central obesity, elevated triglyceride, and elevated ALT levels among freshmen. Second, we were not sure whether the definition of adult metabolic syndrome is applicable to adolescents and young adults. A commonly encountered problem with the use of ALT as a populationbased screening test is related to the cutoff value used to detect normality [6]. Third, the sensitivity and specificity of ALT values in discerning hepatic steatosis and steatohepatitis are variable [40]. Fourth, we did not perform further diagnostic tests to prove NAFLD, such as abdominal ultrasonography or biopsy study. Fifth, we could not completely exclude other types of hepatitis among the study subjects but we could omit this because these other types are rare.

In conclusion, we suggest that aggressive lifestyle modification in young adults is very important for reducing the morbidity associated with the metabolic syndrome, not only cardiovascular disease but also fatty liver disease. Childhood manifestation of metabolic syndrome is likely to continue into adulthood, and early identification may help target interventions to prevent future morbidities. We further emphasize that measurement of waist circumference is a simple, inexpensive, and reliable tool that should be included as part of physical examinations in the routine school-entry health examination. We are looking forward to more prospective study for metabolic syndrome and NAFLD in adolescents and young adults.

\section{References}

[1] Clark JM, Brancati FL, Diehl AM. Nonalcoholic fatty liver disease. Gastroenterology 2002;122:1649-57.

[2] Marchesini G, Brizi M, Bianchi G, et al. Nonalcoholic fatty liver disease: a feature of the metabolic syndrome. Diabetes 2001;50: 1844-50.

[3] Brunt EM. Nonalcoholic steatohepatitis. Semin Liver Dis 2004;24: 3-20.

[4] Cruz ML, Shaibi GQ, Weigensberg MJ, et al. Pediatric obesity and insulin resistance: chronic disease risk and implications for treatment and prevention beyond body weight modification. Annu Rev Nutr 2005;25:435-68. 
[5] Daniel S, Ben-Menachem T, Vasudevan G, et al. Prospective evaluation of unexplained chronic liver transaminase abnormalities in asymptomatic and symptomatic patients. Am J Gastroenterol 1999; 94:3010-4.

[6] Clark JM, Brancati FL, Diehl AM. The prevalence and etiology of elevated aminotransferase levels in the United States. Am J Gastroenterol 2003;98:960-7.

[7] Chen DS, Sung JL. Hepatitis B virus infection on Taiwan. N Engl J Med 1977;297:668-9.

[8] Chien YC, Jan CF, Kuo HS, et al. Nationwide hepatitis B vaccination program in Taiwan: effectiveness in the 20 years after it was launched. Epidemiol Rev 2006;28:126-35.

[9] Jan CF, Chen CJ, Chiu YH, et al. A population-based study investigating the association between metabolic syndrome and hepatitis $\mathrm{B} / \mathrm{C}$ infection (Keelung Community-based Integrated Screening study No. 10). Int J Obes (Lond) 2006;30:794-9.

[10] Hwang LC, Bai CH, Chen CJ. Prevalence of obesity and metabolic syndrome in Taiwan. J Formos Med Assoc 2006;105:626-35.

[11] Alberti KG, Zimmet P, Shaw J. The metabolic syndrome-a new worldwide definition. Lancet 2005;366:1059-62.

[12] Tan CE, Ma S, Wai D, et al. Can we apply the National Cholesterol Education Program Adult Treatment Panel definition of the metabolic syndrome to Asians? Diabetes Care 2004;27:1182-6.

[13] Bureau of Health Promotion, Department of Health, Taiwan. The Criteria of Metabolic Syndrome. 2005.

[14] Ruhl CE, Everhart JE. Determinants of the association of overweight with elevated serum alanine aminotransferase activity in the United States. Gastroenterology 2003;124:71-9.

[15] Kangro HO, Osman HK, Lau YL, et al. Seroprevalence of antibodies to human herpesviruses in England and Hong Kong. J Med Virol 1994;43:91-6.

[16] Shen YH, Yang WS, Lee TH, et al. Bright liver and alanine aminotransferase are associated with metabolic syndrome in adults. Obes Res 2005;13:1238-45.

[17] Fan JG, Zhu J, Li XJ, et al. Prevalence of and risk factors for fatty liver in a general population of Shanghai, China. J Hepatol 2005;43: $508-14$.

[18] Hamaguchi M, Kojima T, Takeda N, et al. The metabolic syndrome as a predictor of nonalcoholic fatty liver disease. Ann Intern Med 2005;143:722-8.

[19] Liangpunsakul S, Chalasani N. Relationship between unexplained elevations in alanine aminotransferase and serum leptin in U.S. adults: results from the Third National Health and Nutrition Examination Survey (NHANES III). J Clin Gastroenterol 2004;38:891-7.

[20] Park HS, Han JH, Choi KM, et al. Relation between elevated serum alanine aminotransferase and metabolic syndrome in Korean adolescents. Am J Clin Nutr 2005;82:1046-51.

[21] Bedogni G, Miglioli L, Masutti F, et al. Prevalence of and risk factors for nonalcoholic fatty liver disease: the Dionysos nutrition and liver study. Hepatology 2005;42:44-52.

[22] Rocha R, Cotrim HP, Carvalho FM, et al. Body mass index and waist circumference in non-alcoholic fatty liver disease. J Hum Nutr Diet $2005 ; 18: 365-70$.

[23] Guzzaloni G, Grugni G, Minocci A, et al. Liver steatosis in juvenile obesity: correlations with lipid profile, hepatic biochemical parame- ters and glycemic and insulinemic responses to an oral glucose tolerance test. Int J Obes Relat Metab Disord 2000;24:772-6.

[24] Manton ND, Lipsett J, Moore DJ, et al. Non-alcoholic steatohepatitis in children and adolescents. Med J Aust 2000;173:476-9.

[25] Schwimmer JB, Deutsch R, Rauch JB, et al. Obesity, insulin resistance, and other clinicopathological correlates of pediatric nonalcoholic fatty liver disease. J Pediatr 2003;143:500-5.

[26] Chan DF, Li AM, Chu WC, et al. Hepatic steatosis in obese Chinese children. Int J Obes Relat Metab Disord 2004;28:1257-63.

[27] Janssen I, Heymsfield SB, Allison DB, et al. Body mass index and waist circumference independently contribute to the prediction of nonabdominal, abdominal subcutaneous, and visceral fat. Am J Clin Nutr 2002;75:683-8.

[28] Taylor RW, Jones IE, Williams SM, et al. Evaluation of waist circumference, waist-to-hip ratio, and the conicity index as screening tools for high trunk fat mass, as measured by dual-energy X-ray absorptiometry, in children aged 3-19 y. Am J Clin Nutr 2000;72: $490-5$.

[29] Wang J. Waist circumference: a simple, inexpensive, and reliable tool that should be included as part of physical examinations in the doctor's office. Am J Clin Nutr 2003;78:902-3.

[30] Sanyal AJ. Mechanisms of disease: pathogenesis of nonalcoholic fatty liver disease. Nat Clin Pract Gastroenterol Hepatol 2005;2: $46-53$.

[31] Kahn HS, Valdez R. Metabolic risks identified by the combination of enlarged waist and elevated triacylglycerol concentration. Am J Clin Nutr 2003;78:928-34.

[32] Perseghin G, Bonfanti R, Magni S, et al. Insulin resistance and whole body energy homeostasis in obese adolescents with fatty liver disease. Am J Physiol Endocrinol Metab 2006;291:E697-703.

[33] Berenson GS, Srinivasan SR, Cresanta JL, et al. Dynamic changes of serum lipoproteins in children during adolescence and sexual maturation. Am J Epidemiol 1981;113:157-70.

[34] Boulton TJ, Magarey AM, Cockington RA. Serum lipids and apolipoproteins from 1 to 15 years: changes with age and puberty, and relationships with diet, parental cholesterol and family history of ischaemic heart disease. Acta Paediatr 1995;84:1113-8.

[35] Harrell JS, Jessup A, Greene N. Changing our future: obesity and the metabolic syndrome in children and adolescents. J Cardiovasc Nurs 2006;21:322-30.

[36] Raitakari OT, Porkka KV, Ronnemaa T, et al. The role of insulin in clustering of serum lipids and blood pressure in children and adolescents. The Cardiovascular Risk in Young Finns Study. Diabetologia 1995;38:1042-50.

[37] Cruz ML, Weigensberg MJ, Huang TT, et al. The metabolic syndrome in overweight Hispanic youth and the role of insulin sensitivity. J Clin Endocrinol Metab 2004;89:108-13.

[38] Berenson GS, Radhakrishnamurthy B, Srinivasan SR, et al. Plasma glucose and insulin levels in relation to cardiovascular risk factors in children from a biracial population-the Bogalusa Heart Study. J Chronic Dis 1981;34:379-91.

[39] Bergstrom E, Hernell O, Persson LA, et al. Insulin resistance syndrome in adolescents. Metabolism 1996;45:908-14.

[40] Choudhury J, Sanyal AJ. Clinical aspects of fatty liver disease. Semin Liver Dis 2004;24:349-62. 